(C)2005 IEEE. Personal use of this material is permitted. However, permission to reprint/republish this material for advertising or promotional purposes or for creating new collective works for resale or redistribution to servers or lists, or to reuse any copyrighted component of this work in other works must be obtained from the IEEE. 


\title{
Capacity Improvements for Rural Single Wire Earth Return Systems
}

\author{
P.J.Wolfs, Senior Member, IEEE
}

\begin{abstract}
The single wire earth return, (SWER), system is a low cost power distribution method that finds international use in rural areas. It is a key technology for the extension of grid systems. In Australia, SWER systems can cover vast areas. A single SWER system may typically supply $100 \mathrm{~kW}$ to several dozen customers and may extend more than $300 \mathrm{~km}$. Recent changes in the Australian retail energy market structure and significant load growth are driving a requirement for new low cost methods of capacity improvement. Shunt reactors are often used in SWER systems to compensate for line charging current effects. As voltage regulation is the determining capacity factor, the replacement of fixed shunt reactors with controllable reactors provides an opportunity to significantly increase the system capacity. A case study of the North Jericho SWER system is presented which shows a capacity increase of approximately $85 \%$ can be achieved.
\end{abstract}

Index Terms-Power Distribution, reactive power control, rural areas, thyristor applications, voltage control.

\section{INTRODUCTION}

$\mathrm{S}$ INGLE wire earth return, (SWER), systems find broad international use for power distribution in regions where the load density is relatively low, [1]. In the developing world, they offer the lowest costs for grid extension. They are typically constructed as spur extensions from three phase systems. In Australia, the distribution voltage is typically $12.7 \mathrm{kV}$ or $19.1 \mathrm{kV}$, the phase to ground voltages for $22 \mathrm{kV}$ or $33 \mathrm{kV}$ three phase systems, [2]. While it is possible to directly connect SWER systems to the phases of a three phase systems, isolating transformers are normally used to allow the use of earth fault protection on the three phase line.

In many areas of Australia including Central Queensland, many rural electrification systems had been established by state owned electricity boards during the sixties, seventies and eighties under community service initiatives. SWER systems would typically supply loads of $100 \mathrm{kVA}$ to $200 \mathrm{kVA}$ scattered over a line length that might exceed $300 \mathrm{~km}$. The load density is low and typically $0.5 \mathrm{kVA} / \mathrm{km}$, [3]. To reduce the construction costs all steel or steel/aluminium composite conductors are often used to achieve large span lengths.

Consumers are connected by a single phase transformer with two single phase outputs in a 240V-0-240V centre tapped arrangement. In earlier Central Queensland systems a

P.J.Wolfs is with the Faculty of Engineering and Physical Systems, Central Queensland University, Rockhampton 4701, Queensland, Australia. (e-mail: p.wolfs@cqu.edu.au). consumer transformer was typically $10 \mathrm{kVA}$ but this has now increased to $25 \mathrm{kVA}$ for a standard connection. Figure 1 shows a typical single phase installation.

As the Australian power industry has progressively privatized, the capital expenditures on these systems have been more restricted. Improvements to cater for load growth are difficult to justify from the revenues that these lightly loaded systems produce. Power quality and reliability issues have emerged that have resulted in the establishment of a SWER task force in Queensland. New technical solutions that offer lower capital costs than reconstruction or the replacement of conductors are required.

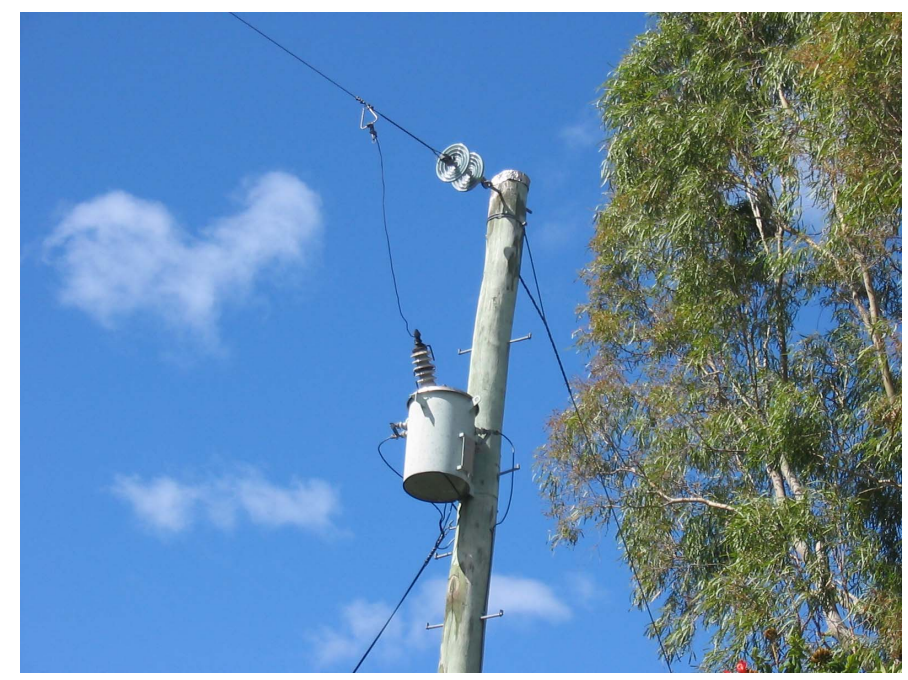

Fig 1. A Single Wire Earth Return Consumer Connection Transformer

\section{POWER QUALITY AND CAPACITY LIMITATIONS}

Voltage regulation is the major capacity limitation for the existing SWER systems. The conductors have significant resistive losses and the $\mathrm{R} / \mathrm{X}$ ratio for SWER systems is relatively high. While higher intermediate voltages can be used, [4], these solutions are very limited in the Australian situation.

Power electronic solutions to SWER voltage regulation problem have been proposed, [5]. It is possible to rectify the incoming grid supply and re-invert to produce a high quality supply at a consumer connection point to alleviate even extreme voltage regulation issues. These solutions are more technically complex but are certainly achievable. A slightly less inverter intensive solution is to use an inverter to provide 
a series connected compensating voltage to condition the consumers power, [6]. The introduction of distributed generation is also a possibility, [7]-[8]. Real power support could be provided by solar or diesel generation or from batteries that are charged at periods of light loading.

Many SWER systems include shunt reactors to control the effects of the line charging capacitance. One effect, the Ferranti effect, causes the line voltage to rise with distance. In most distribution systems this effect is not particularly visible but in SWER systems this effect is so pronounced as to make it difficult to maintain the consumers supply within the acceptable regulation range. A second effect of the line capacitance is to increase the loading of the SWER system supply transformer. In SWER systems the line charging current may be as high as twice the supply transformer rating. Shunt reactors may be needed to allow a moderately sized transformer to excite the line.

In a SWER system that is suffering from under voltage at heavier loads, an obvious solution is to add some element of control to the shunt reactors.

\section{CONTROLLABLE SHUNT REACTORS}

The industry has always recognized the immediate advantages in removing the reactors at higher loads. There have been considerable costs attached to this. While the reactors are small, typically $25 \mathrm{kVAr}$ or approximately 1.3 Arms at $19 \mathrm{kV}$, a switchable reactor will require a motorized high voltage switch, a voltage transformer and a suitable control element. The switch and the voltage transformers will have minimum costs that are much more influenced by the voltage rating than the reactor current. The resulting minimum costs are relatively high.

An alternative to switching on the high voltage side is to switch at lower voltages on a transformer secondary. Consumer transformers of $25 \mathrm{kVA}$ rating are produced in large quantities and are consequently moderately priced. Shunt reactors rated at $19 \mathrm{kV}$ can readily be replaced by an inductors rated at $480 \mathrm{~V}$ connected across the secondary of a $25 \mathrm{kVA}$ $19 \mathrm{kV}$ to $240 \mathrm{~V}-0-240 \mathrm{~V}$ transformer. This then allows the switching to be performed at low voltages.

Either conventional contactors or thyristors can be readily applied. For a typical $25 \mathrm{kVAr}$ reactor, the thyristor switch will introduce approximately $100 \mathrm{~W}$ in conduction loss due to its forward drop but mechanical contacts, and corresponding wear will be avoided. A further advantage of a thyristor element is the capacity for phase control. A relatively simple microprocessor or even an analogue controller will give a capacity to continuously vary the inductor current. It now becomes possible to replace the reactor with a controllable voltage regulation device at relatively low cost. As an indication only, the costs of a controlled device are expected to be in the $\$ 10000$ USD range.

The paper will show that this approach can be readily applied to a SWER system and will yield a significant increase in system capacity by effectively removing the shunt reactors as the system voltage falls under load. The Jericho North system will be presented as a case study that highlights the scale and complexity of Australian SWER systems. This case study will also critically examine two important operational issues for this solution, namely the impact on the supply transformer loading and the potential for harmonic generation.

\section{THE JERICHO NORTH CASE STUDY}

The Jericho North SWER system is between Barcaldine and Alpha in Central Queensland, [9]. A simplified schematic is shown in Figure 2. This is a rural area focussed on the production of beef. The transmission voltage is $19 \mathrm{kV}$ and system supplies 43 consumer load points, many of which are bores or pumps. Two of the load points are $25 \mathrm{kVA}$ transformers and the others are 10kVA giving a total consumer transformer connection of 460kVA. The SWER system bulk supply transformer is rated at $150 \mathrm{kVA}$. A total of nine shunt reactors are distributed across the system each with a $25 \mathrm{kVAr}$ rating. The SWER system is arranged as a backbone conductor with lighter spur conductors. The back bone is $141 \mathrm{~km}$ of $3 / 4 / 2.5 \mathrm{ACSR} / \mathrm{GZ}$, a conductor with three aluminium and four steel conductors. The spurs total $223 \mathrm{~km}$ of $3 / 2.75 \mathrm{SC} / \mathrm{GZ}$, an all steel three strand conductor. Table I contains the conductor parameters, notice the all steel conductor has a very high resistance relative to its reactance.

TABLE I

SINGLE WIRE EARTH RETURN CONDUCTOR PROPERTIES

\begin{tabular}{|c|c|}
\hline Conductor & Parameters \\
\hline $\mathbf{3} / \mathbf{4} / \mathbf{2 . 5}$ & R0: $2.02 \Omega / \mathrm{km} ; \mathrm{X} 0: 0.802 \Omega / \mathrm{km}$ \\
ACSR/GZ & B1: $2.086 \mu \mathrm{mho} / \mathrm{km}$ \\
\hline $\mathbf{3 / 2 . 7 5}$ & R0: $12.55 \Omega / \mathrm{km} ; \mathrm{X} 0: 0.819 \Omega / \mathrm{km}$ \\
$\mathbf{S C} / \mathbf{G Z}$ & $\mathrm{B} 1: 2.029 \mu \mathrm{mho} / \mathrm{km}$ \\
\hline
\end{tabular}

The line capacitance generates a capacitive charging requirement of $753 \mathrm{VAr} / \mathrm{km}$ for the $3 / 4 / 2.5 \mathrm{ACSR} / \mathrm{GZ}$ backbone conductor and $732 \mathrm{VAr} / \mathrm{km}$ for the $3 / 2.75 \mathrm{SC} / \mathrm{GZ}$ conductor. Over the $364 \mathrm{~km}$ of the SWER system this becomes a total capacitive loading of $270 \mathrm{kVAr}$. The need for $225 \mathrm{kVAr}$ of shunt reactors is now apparent, the line capacitive current is $180 \%$ of the supply transformer rating. The existing transformer is incapable of energising the line without the reactors present. After the addition of the reactors the transformer loading at no consumer load is expected to be approximately $45 \mathrm{kVAr}$ leading with real power components largely caused by the reactor and consumer transformer core losses.

\section{THYRISTOR CONTROLLED REACTOR SYSTEM}

This paper proposes the substitution of each fixed shunt reactor by a thyristor controlled reactors coupled via a standard $25 \mathrm{kVA} 19 \mathrm{kV}$ to $240 \mathrm{~V}-0-240 \mathrm{~V}$ transformer as shown in Figure 3. It will be later shown that it is preferable from a harmonic current viewpoint to split the $25 \mathrm{kVAr}$ inductor into 
two halves that are sequentially controlled. The TCR is to be controlled to regulate the voltage at the local point of connection. Above the regulation set point voltage, in this case $19 \mathrm{kV}$, the thyristor firing angle is progressively adjusted to increase the inductor current. In this study the voltage at the point of connection was detected with an independent voltage transducer. A proportional-integral control action is used with the following gain settings:

- Proportional Gain: A voltage error of $500 \mathrm{~V}_{\mathrm{rms}}$ yields rated inductor current;

- Integral Gain: A voltage error integral of $500 \mathrm{~V}_{\mathrm{rms}}$ seconds yields rated inductor current.
An alternative for physical implementation is to determine the connection point voltage from the transformer secondary. Some error will be introduced by the transformer impedance and the resulting voltage regulation but this is known and in principle a feed forward correction can be made as a function of the inductor current. Some voltage distortion will be present at the secondary terminals due the conduction of the thyristors. A practical solution is to base the thyristor phase control upon the integral of the transformer secondary voltage. The zero crossing of this waveform has high noise immunity and accurately locates the point $\alpha=90^{\circ}$ which is the point of minimum firing delay, and maximum current, for a TCR.

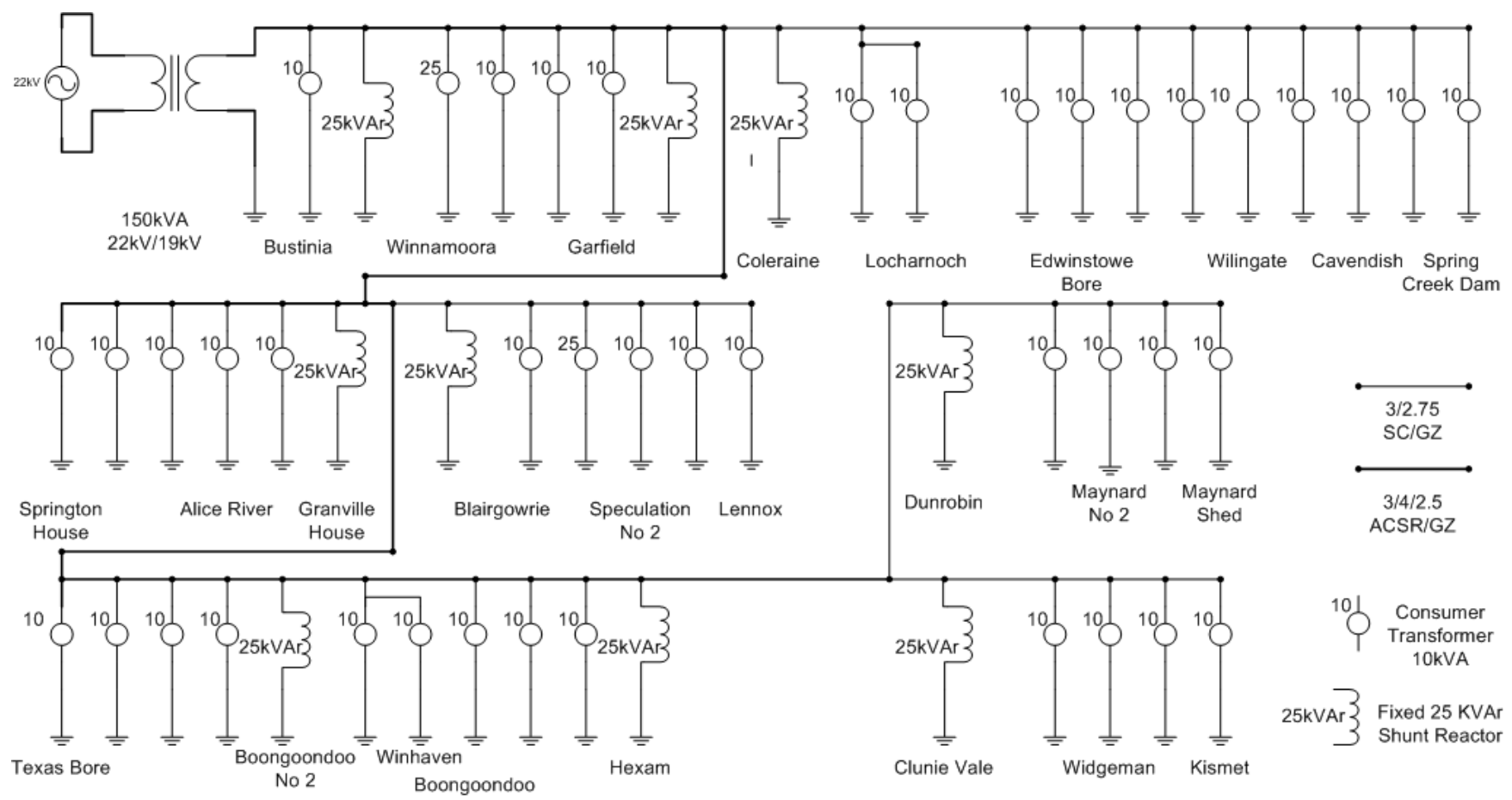

Fig. 2. Simplified Jericho North System Diagram

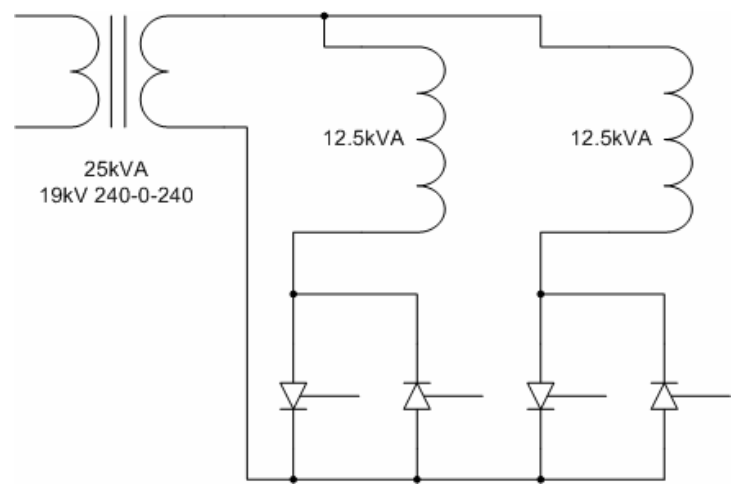

Fig. 3. Sequentially Controlled Dual Inductor TCR Implementation

\section{SIMULATION STUDIES}

The Jericho North System is studied using time domain simulations with the Matlab Simulink Power Systems Block Set. This is a time domain simulator with both a control systems and power electronics modeling capacity. As the thyristor controlled reactors can be modeled on a cycle by cycle basis, the harmonic performance of the system is observable as is the full range of TCR control behaviors. If simulations are run over some seconds of operation, that is a few hundred cycles, any interaction of TCR control systems can be observed. This modeling approach provides a great deal of insight but is rather time consuming with simulations taking several hours to complete on a desk top machine. The model features are:

- $\quad$ The topological layout of the simulation network follows precisely the construction drawings of the physical 
network, a total of 76 transmission line sections are identified and modeled;

- $\pi$ section models are used and any physical section over $10 \mathrm{~km}$ in length is broken into equal length multiple $\pi$ sections of a maximum $10 \mathrm{~km}$ in length; $10 \mathrm{~km}$ corresponds to a quarter wavelength frequency of $7.5 \mathrm{kHz}$, the simulations will show the highest frequency of any significance is $150 \mathrm{~Hz}$;

- The reactors have a Q factor of 50 , that is a $2 \%$ loss factor modeled as a 0.02 per unit series resistance;

- The bulk supply $22 \mathrm{kV}$ to $19 \mathrm{kV}$ transformer turns ratio is $22 \mathrm{kV}: 19 \mathrm{kV}$; It has series impedances of 0.016 per unit resistance and 0.038 per unit reactance; The magnetizing branch resistance and reactance are 100 per unit and 200 per unit respectively;

- $\quad$ The $22 \mathrm{kV}$ system is modeled as an infinite bus supply;

- Each consumer connection is modeled with a single phase transformer with series branch per unit resistance and reactance of 0.026 and 0.025 per unit; The magnetising branch resistance and reactance are 100 and 200 per unit respectively; The turns ratio is $19 \mathrm{kV}$ to 240V-0-240V;

- Consumer loads are modeled as linear constant impedance loads at 0.8 power factor calculated at $240 \mathrm{~V}$; consumer loads are distributed over each consumer connection transformer at a fixed percentage of the transformer rating.

Base line studies of the existing system are first conducted with the fixed shunt reactors in place. Four loading conditions are studied, these are:

- $\quad$ No connected consumer load;

- Consumer loads, uniformly distributed as a percentage of each consumer transformer rating, with cases of 50kVA, $100 \mathrm{kVA}$ and $150 \mathrm{kVA}$ of total network loading.

The 150kVA load case for example corresponds to $32.6 \%$ loading at each consumer transformer. The load is represented as a linear constant impedance model with a series connected resistance and inductance component. Table II reports the system voltage at the location of each reactor. The first nine sites listed are reactor locations ordered according to distance from the point of supply. Maynard Shed and Kismet are equally the most distant load points in the SWER system. Spring Creek Dam, Lenox and Springton House are at the ends of the major spur lines. The last five sites will be the points that determine the system capacity due to voltage drop.

At no load the residual effects of the line capacitance elevate the voltages by as much as $2 \%$ above nominal, with points such as Kismet reaching $19.38 \mathrm{kV}$. For comparative purposes a low voltage limit of $-6 \%$ below nominal system voltage, or $17.86 \mathrm{kV}$ is selected for the HV system. At this point the system is deemed to be fully loaded. At $150 \mathrm{kVA}$ many sites fall below this limit and this is indicated by yellow shading of the affected cells in Table 2. Maynard Shed records $17.47 \mathrm{kV}$ or $8.0 \%$ below nominal voltage. An estimate of system capacity can be made by interpolating between the results for $100 \mathrm{kVA}$ and $150 \mathrm{kVA}$ loading to estimate the load resulting in a $6 \%$ drop at this location. The result is $114 \mathrm{kVA}$ and this is the estimated load capacity of the existing SWER system.

TABLE II

SYSTEM VOLTAGES $(\mathrm{kV})$ WITH FIXED REACTORS

\begin{tabular}{|c|c|c|c|c|}
\hline Location & $\begin{array}{c}\text { No } \\
\text { Load }\end{array}$ & $\mathbf{5 0}$ kVA & $\begin{array}{c}\mathbf{1 0 0} \\
\text { kVA }\end{array}$ & $\begin{array}{c}\mathbf{1 5 0} \\
\text { kVA }\end{array}$ \\
\hline Bustinia & 19.27 & 19.00 & 18.76 & 18.58 \\
\hline Garfield & 19.35 & 18.84 & 18.40 & 18.03 \\
\hline Coleraine & 19.34 & 18.78 & 18.28 & 17.87 \\
\hline $\begin{array}{c}\text { Granville } \\
\text { House }\end{array}$ & 19.36 & 18.81 & 18.33 & 17.93 \\
\hline $\begin{array}{c}\text { Blairgowrie } \\
\text { Boongoondoo } \\
\text { No 2 }\end{array}$ & 19.35 & 18.74 & 18.19 & 17.73 \\
\hline Hexam & 19.37 & 18.71 & 18.14 & 17.65 \\
\hline $\begin{array}{c}\text { ClunieVale } \\
\text { Dunrobin }\end{array}$ & 19.37 & 18.69 & 18.10 & 17.59 \\
\hline $\begin{array}{c}\text { Maynard } \\
\text { Shed }\end{array}$ & 19.38 & 18.65 & 18.02 & 17.47 \\
\hline Kismet & 19.38 & 18.67 & 18.04 & 17.50 \\
\hline $\begin{array}{c}\text { Spring Creek } \\
\text { Dam }\end{array}$ & 19.35 & 18.65 & 18.02 & 17.49 \\
\hline Lenox & 19.34 & 18.73 & 18.17 & 17.69 \\
\hline $\begin{array}{c}\text { Springton } \\
\text { House }\end{array}$ & 19.37 & 18.78 & 18.25 & 17.82 \\
\hline
\end{tabular}

Controlled reactors were introduced and the system loading was progressively increased. To reduce run times in the voltage regulation studies each $25 \mathrm{kVAr}$ controlled reactor is modeled by a single controlled inductor. Only selected cases were run with each controlled reactor implemented as a pair of inductors. This affects the harmonic levels but not the fundamental voltage regulation results.

Table III reveals the results. Very significant gains in capacity have been made, less of the system is below the $-6 \%$ limit at $250 \mathrm{kVA}$ of load than was seen for the original system at $150 \mathrm{kVA}$ loading. Spring Creek Dam is now the controlling point in terms of voltage regulation, this is at the end of long spur using all steel conductors and emerges as a weak point under higher loadings. Interpolation between the $200 \mathrm{kVA}$ and $250 \mathrm{kVA}$ load case suggest the $-6 \%$ limit is reached at $212 \mathrm{kVA}$ of loading. This is an increase of $85 \%$. 
TABLE III

SYSTEM VOLTAGES $(\mathrm{kV})$ WITH THYRISTOR CONTROLLED REACTORS

\begin{tabular}{|c|c|c|c|c|c|c|}
\hline Location & 0 kVA & $50 \mathrm{kVA}$ & $100 \mathrm{kVA}$ & $150 \mathrm{kVA}$ & $200 \mathrm{kVA}$ & $250 \mathrm{kVA}$ \\
\hline Bustinia & 19.27 (full) & 19.17 (full) & 19.26 (full) & 19.34 (full) & 19.14 (full) & 19.03 (out) \\
\hline Garfield & 19.35 (full) & 19.08 (full) & 19.07 (full) & $\begin{array}{c}19.06 \\
\text { (regulating) }\end{array}$ & 18.70 (out) & 18.4 (out) \\
\hline Coleraine & 19.34 (full) & $\begin{array}{c}19.02 \\
\text { (regulating) }\end{array}$ & 18.97 (out) & 18.90 (out) & 18.49 (out) & 18.15 (out) \\
\hline $\begin{array}{c}\text { Granville } \\
\text { House }\end{array}$ & 19.36 (full) & 19.06 (full) & 19.05 (full) & $\begin{array}{c}19.03 \\
\text { (regulating) }\end{array}$ & 18.63 (out) & 18.29 (out) \\
\hline Blairgowrie & 19.35 (full) & $\begin{array}{c}19.01 \\
\text { (regulating) }\end{array}$ & $\begin{array}{c}18.98 \\
\text { (regulating) }\end{array}$ & 18.91 (out) & 18.44 (out) & 18.04 (out) \\
\hline $\begin{array}{c}\text { Boongoondoo } \\
\text { No } 2\end{array}$ & 19.38 (full) & 19.03 (full) & $\begin{array}{c}19.02 \\
\text { (regulating) }\end{array}$ & 18.98 (out) & 18.50 (out) & 18.10 (out) \\
\hline Hexam & 19.37 (full) & $\begin{array}{c}19.01 \\
\text { (regulating) }\end{array}$ & $\begin{array}{c}19.01 \\
\text { (regulating) }\end{array}$ & 18.97 (out) & 18.46 (out) & 18.04 (out) \\
\hline Clunie Vale & 19.37 (full) & $\begin{array}{c}19.00 \\
\text { (regulating) }\end{array}$ & $\begin{array}{c}18.99 \\
\text { (regulating) }\end{array}$ & 18.94 (out) & 18.42 (out) & 17.98 (out) \\
\hline Dunrobin & 19.37 (full) & $\begin{array}{c}18.99 \\
\text { (regulating) }\end{array}$ & $\begin{array}{c}18.98 \\
\text { (regulating) }\end{array}$ & 18.92 (out) & 18.40 (out) & 17.96 (out) \\
\hline $\begin{array}{l}\text { Maynard } \\
\text { Shed }\end{array}$ & 19.38 & 18.96 & 18.91 & 18.81 & 18.25 & 17.78 \\
\hline Kismet & 19.38 & 18.98 & 18.93 & 18.85 & 18.30 & 17.84 \\
\hline $\begin{array}{c}\text { Spring Creek } \\
\text { Dam }\end{array}$ & 19.35 & 18.88 & 18.69 & 18.50 & 17.97 & 17.51 \\
\hline Lenox & 19.34 & 19.00 & 18.95 & 18.87 & 18.38 & 17.97 \\
\hline $\begin{array}{c}\text { Springton } \\
\text { House }\end{array}$ & 19.37 & 19.02 & 18.97 & 18.91 & 18.47 & 18.10 \\
\hline
\end{tabular}

\section{SENDING END TRANSFORMER CAPACITY}

The use of TCRs improves voltage regulation across the system and allows a significant capacity expansion that can only be realised if the sending end transformer capacity is increased. The currents would be well within the capacities of the conductors used. Table IV shows the transformer loading for the existing situation. The reactors and transformers contribute $4.6 \mathrm{~kW}$ and $4.7 \mathrm{~kW}$ of the no load loss respectively.

Table $\mathrm{V}$ shows the same results for the TCR equipped system. It should be noted that the real power in the load models will vary with the system voltage regulation. These tables should not be used to compare the system losses. The real powers developed by the load models are higher in the TCR controlled system as the consumer voltages are higher.

To maintain voltage regulation at higher loads, the TCRs reduce their inductive current demand exposing the transformer to higher levels of capacitive current. At loadings of 50kVA and 100kVA, Table 3 shows a rise in the voltage at Bustinia. This is due to the action of the reactors at the remote ends of the line resulting in an increase in capacitive current at the sending end. The higher system capacity can only be accessed if the transformer rating increases. The existing system contains $364 \mathrm{~km}$ of conductor probably representing a sunk cost exceeding \$2 million USD. A transformer upgrade is certainly a viable option and much cheaper than reconstruction.

\section{HARMONICS}

Thyristor controlled reactors do generate harmonic currents that are a considerable fraction of the fundamental current, [10]. Figure 4 shows the variation in the fundamental current in per unit terms while Figure 5 shows the variation in the third harmonic, the largest current harmonic, with firing angle, $\alpha$. The third harmonic peaks at $38 \%$ of the reactor rated fundamental current at a delay angle, $\alpha=141^{\circ}$. An important 
feature of the TCR device is that, if driven by a sinusoidal voltage source, $\mathrm{V}_{\mathrm{p}} \sin (\omega \mathrm{t})$, only odd cosine harmonics are present as the current waveform is symmetric around $\omega t=0$, [9]. Unlike other thyristor controlled devices there is no variation in harmonic phase angle with firing angle. This lack of phase diversity means no cancellation occurs with multiple devices, the harmonics are additive.

TABLE IV

SENDING END TRANSFORMER RATINGS - FIXED SHUNT REACTORS

\begin{tabular}{|c|c|c|c|}
\hline Load & Current & kVA rating & Power kW \\
\hline No Load & 3.23 & 62 & 15 \\
\hline $50 \mathrm{kVA}$ & 3.04 & 58 & 51 \\
\hline $100 \mathrm{kVA}$ & 4.52 & 85 & 85 \\
\hline $150 \mathrm{kVA}$ & 6.46 & 120 & 117 \\
\hline
\end{tabular}

TABLE V

SENDING END TRANSFORMER RATINGS - TCR SOLUTION

\begin{tabular}{|c|c|c|c|}
\hline Load & Current & kVA rating & Power kW \\
\hline No Load & 3.23 & 62 & 15 \\
\hline $50 \mathrm{kVA}$ & 4.47 & 86 & 53 \\
\hline $100 \mathrm{kVA}$ & 7.48 & 144 & 95 \\
\hline $150 \mathrm{kVA}$ & 6.46 & 200 & 139 \\
\hline $200 \mathrm{kVA}$ & 10.8 & 207 & 169 \\
\hline $250 \mathrm{kVA}$ & 11.8 & 225 & 195 \\
\hline
\end{tabular}

Figure 5 shows the worst supply voltage distortions occur when a significant number of reactors are in the regulating range. No harmonics are produced by a TCR in the fully on or off states. A series of investigations showed the 100kVA load case has the highest harmonic impacts of the cases studied. The system reactance has a major impact on the resulting distortion voltages. Figure 6 shows the system impedance for the $100 \mathrm{kVA}$ load case at Dunrobin, located at the end of the SWER system. The impedance at the third harmonic, the dominant TCR current harmonic, is high. A parallel resonance occurs close to $150 \mathrm{~Hz}$ and involves the line to ground capacitance and an inductance which is the combination of the line inductance and the sending end transformer leakage reactance. The resonance peak lifts the reactance at Dunrobin to nearly $1600 \Omega$.

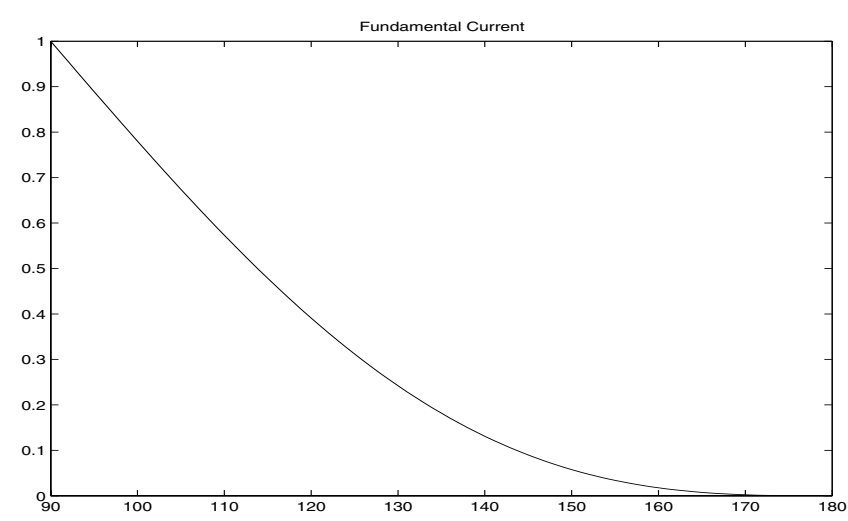

Fig. 4. Per Unit Fundamental Current

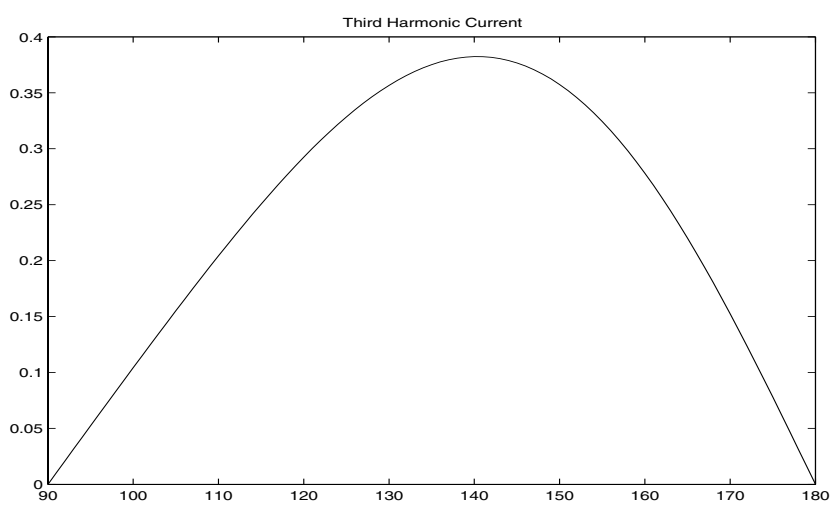

Fig. 5. Per Unit Third harmonic Current.

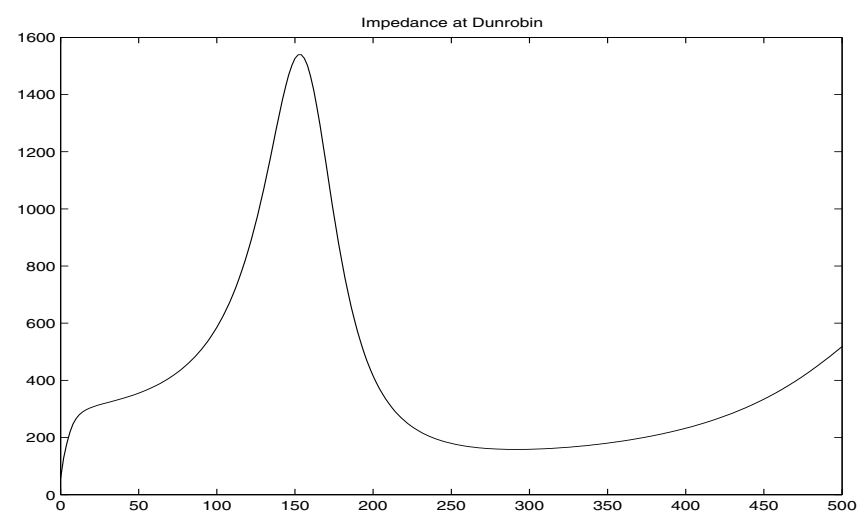

Fig. 6. System Impedance, $(\Omega)$, at Dunrobin, $0-500 \mathrm{~Hz}$.

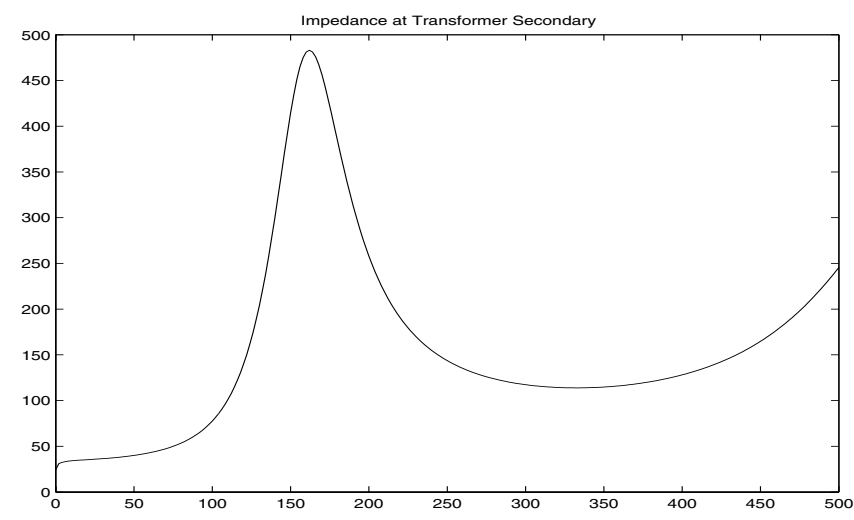

Fig.7. System Impedance, $(\Omega)$, at the Sending End Transformer $19 \mathrm{kV}$ Secondary, $0-500 \mathrm{~Hz}$. 
Bustinia
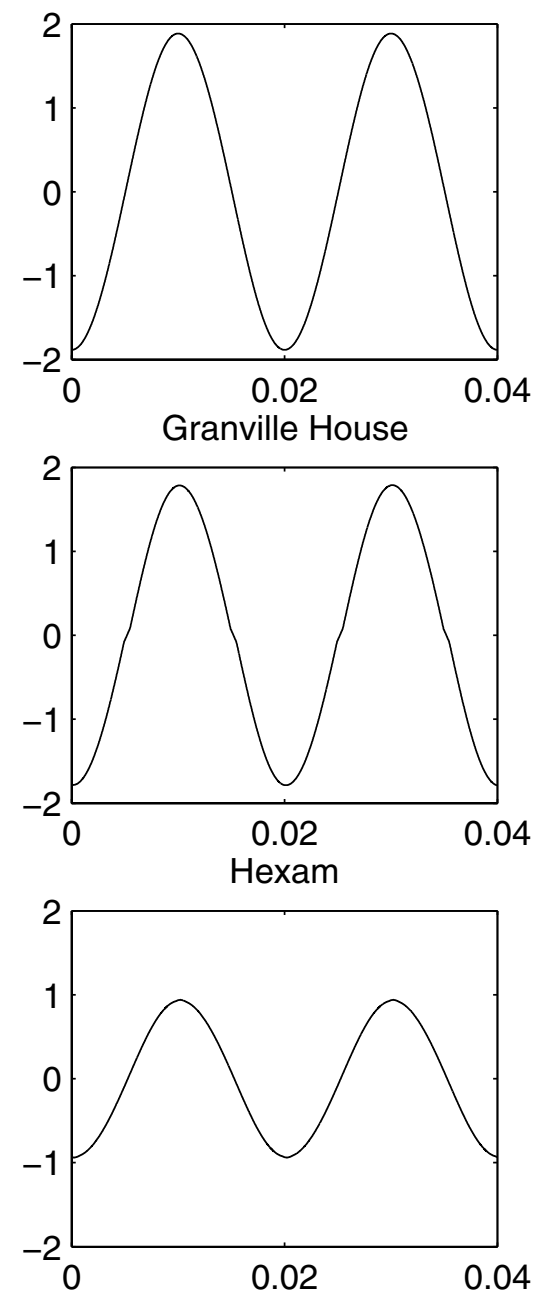

Garfield
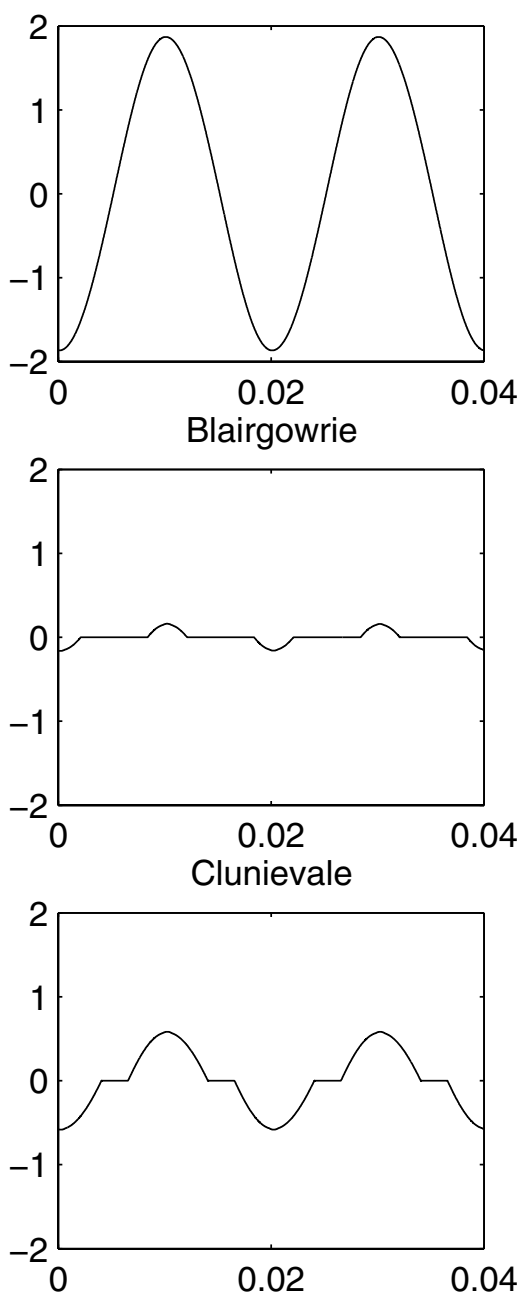

Coleraine
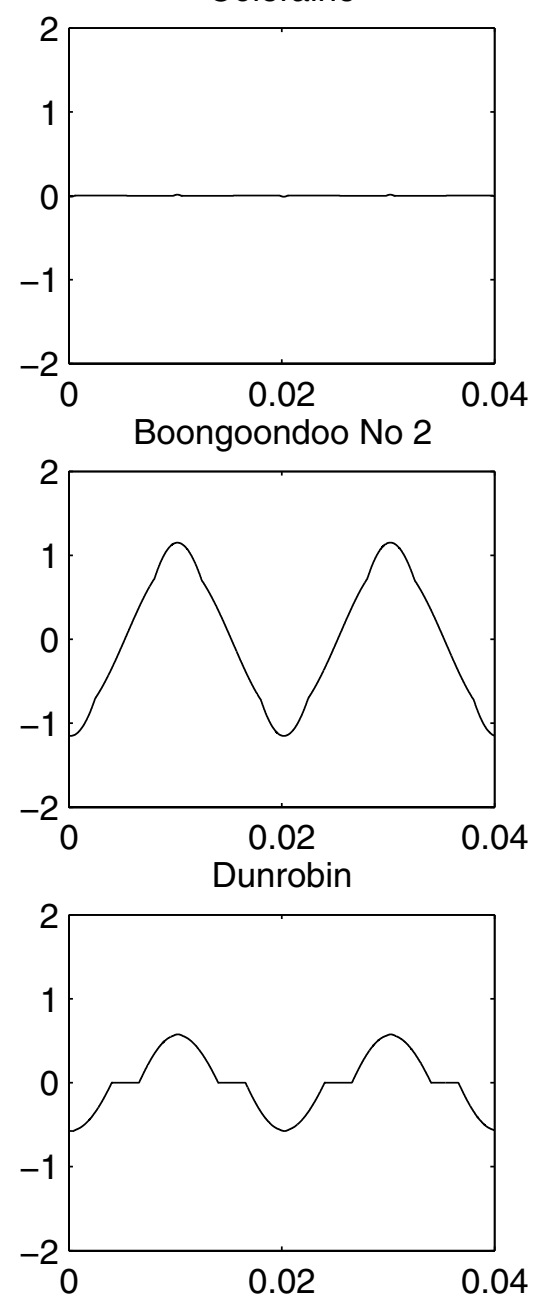

Fig. 8. TCR Currents 100kVA Loading Case

Figure 7 shows the impedance at the transformer secondary. A similar resonance effect is visible but at a higher frequency as the line reactance is absent.

The voltage regulation study used TCRs with a single $25 \mathrm{kVAr}$ inductor and it was found that distortions as high as $5.1 \%$ occurred this site. As this exceed the 4\% limitation imposed by Australian Standard AS 2279 for a single odd harmonic, the studies were re-run with each $25 \mathrm{kVAr}$ TCR implemented using a pair of $12.5 \mathrm{kVAr}$ inductors that are sequentially operated. Sequential operation ensures that only one inductor is proportionally controlled at a time with the second inductor operated fully on or fully off. This halves the distortion current. With this TCR arrangement the worst voltage distortions reduced to $2.2 \%$ for the third harmonic at the Dunrobin site. The higher voltage harmonics are negligible. The higher order TCR currents diminish with harmonic number and Figures 6 and 7 shows a collapse in the system impedance as the effects of line capacitance begins to dominate. Levels for the fifth harmonic voltage at Dunrobin are $0.06 \%$ for example.

Figure 8 shows the nine TCR currents for the $100 \mathrm{kVA}$ loading case. A range of operating states can be seen. The TCRs at Bustinia and Garfield are operating at full capacity while Coleraine is fully removed. Blairgowrie, Clunievale and Dunrobin are operating below $12.5 \mathrm{kVAr}$ on a single inductor. Hexam appears to be operating close to $12.5 \mathrm{kVA}$ on a single inductor. The TCRs at Boongoondoo $\mathrm{No} 2$ and Granville House operate between $12.5 \mathrm{kVAr}$ and $25 \mathrm{kVAr}$ with a one controlled inductor and the remaining inductor section in full conduction.

Figure 9 shows the sending end transformer voltage and current. The voltage waveform contains $1.1 \%$ of third harmonic and negligible $0.06 \%$ of fifth harmonic. For the current, a Fourier analysis shows the fundamental and third harmonic currents to be 7.35Arms and 0.74Arms respectively. Again higher harmonics are negligible with the fifth current harmonic being $0.4 \%$. The third harmonic currents represent $10 \%$ of the fundamental. These enter the $22 \mathrm{kV}$ system but will be significantly cancelled if similar TCR controlled SWER systems are connected across the other phases.

A TCR will only produce odd cosine harmonics. The lack of phase diversity for the TCR devices will ensure that the third harmonic currents will act as zero sequence components if balanced in magnitude. 

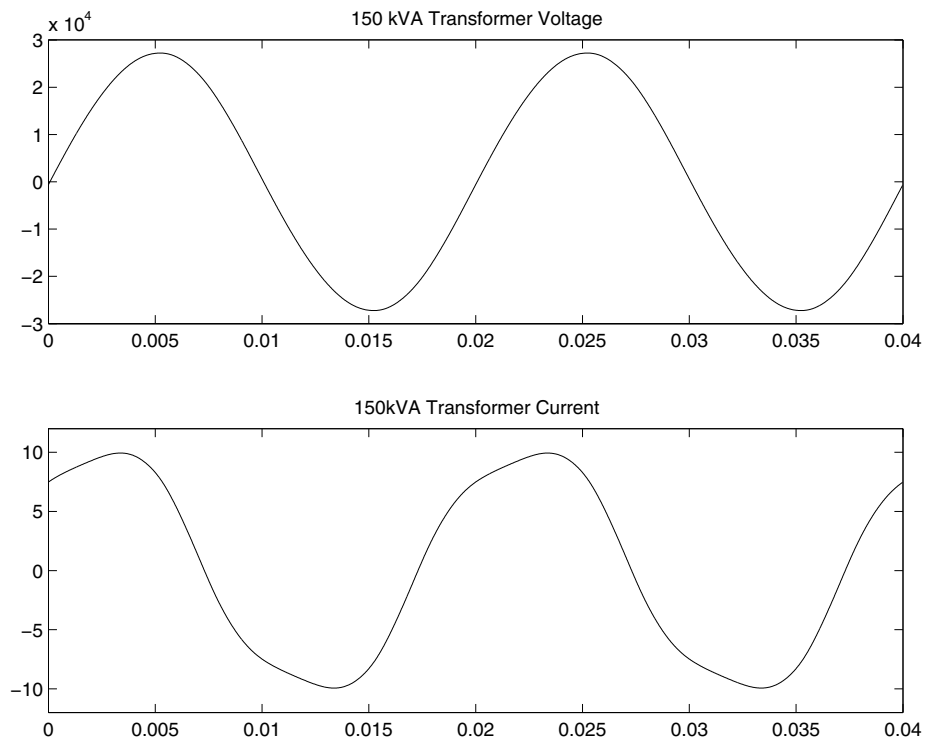

Fig. 8: Sending End Voltage and Current - 100kVA load case.

Normal star-delta connections will largely prevent the third harmonics from leaving the three phase feeder if the connected SWER systems are reasonably balanced and produce comparable levels of third harmonic current.

\section{CONCLUSIONS}

This paper has demonstrated that the replacement of fixed shunt reactors with controlled reactors can provide a low cost method of considerably increasing the capacity of SWER systems and an $85 \%$ improvement in capacity was achieved for a practical case study. The North Jericho case study involved nine controlled reactors distributed across a SWER system with more than $300 \mathrm{~km}$ of conductor. No adverse interaction of the TCR voltage regulation systems was noted and it appears these can operate successfully with only a knowledge of the local voltage. Placement of the reactor on the low voltage side of a conventional transformer allows phase control to be achieved cheaply. The control systems required for the TCR solution are readily implemented in either microprocessor or analogue forms.

The rating of the sending end transformer was examined. The significant increase in system capacity achieved does require that the rating of this transformer increase but this is considered to be a very justifiable expense. The transformer is exposed to an increased capacitive loading in the middle load ranges. This will be reflected on the three phase feeder and the possible impact of this loading on the voltage regulators further upstream is being currently assessed.

The case study presented a detailed study of the harmonic performance of the TCR solution. It was found that the system impedance contains a parallel resonance near the third harmonic involving the line to ground capacitance and the supply transformer reactance. The North Jericho system presents a worst case scenario in terms of the positioning of this resonance. A satisfactory harmonic voltage reduction was readily achieved by implementing the TCRs with a pair of inductors that are sequentially controlled. Some third harmonic current is injected into the three phase feeder but this is unlikely to be troublesome given that significant cancellation will occur.

The solution to single wire earth return capacity enhancement proposed appears to provide a good economic return with relatively low technical risks. TCRs, at the transmission level, are robust and well understood devices. Given the low costs of modern power electronic devices and controls, here is little impediment to their application in SWER applications.

\section{ACKNOWLEDGEMENT}

The author gratefully acknowledges the contributions of Anthony Loveday and Jon Turner of Ergon Energy Limited for the supply of data related to the North Jericho System.

\section{REFERENCES}

[1] Allen R. Inversin, "Reducing the cost of grid extension for rural electrification", NRECA International, Ltd., World Bank Energy Sector Management Assistance Program, ESMAP, February 2000. Available: http://rru.worldbank.org/Documents/PapersLinks/1072.pdf

[2] High Voltage Earth Return for Rural Areas, Fourth Edition, Electricity Authority of New South Wales, June 1978.

[3] N.Chapman, "Australia's rural customers benefit from single wire earth return systems", Trans. Dist., pp56-61, Apr 2001.

[4] T.R.Brooking, N.Janse van Rensburg, R.J.Fourie, "The improved utilization of existing rural networks with the use of intermediate voltage and single wire earth return systems", in Proc. 1992 IEEE AFRICON '92, pp 228-234.

[5] S.Thiel, C. Mostert, J.H.R. Enslin, "Universal power electronic solution to low cost rural electrification", in Proc. 1996 IEEE AFRICON '96, pp 335-340.

[6] H.C. van Niekerk, I.W. Hofsajer, "The use of series injection to eliminate voltage distortion low and medium voltage networks", IEEE Industrial and Commercial Power Systems Conf., 7-11 May 2000, pp16.

[7] M.A.Kashem, G. Ledwich, "Distributed generation as voltage support for single wire earth return systems", IEEE Trans. Power Delivery, Vol. 19, No 3, July 2004, pp1002-1011.

[8] G.Ledwich, "Distributed generation as voltage support for single wire earth return systems", Power Engineering Society General Meeting 2004, Vol 2, pp2176.

[9] Peter Wolfs, Steven Senini, Nasser Hossein-Zadeh, Dawit Seyoum, Anthony Loveday, Jon Turner, "Thyristor Controlled Reactor Methods to Increase the Capacity of Single Wire Earth Return Systems", Australasian Universities Power Engineering Conference, 2005.

[10] W.Shepherd, Thyristor Control of AC Circuits. London: William Clowes and Sons Limited, 1975.

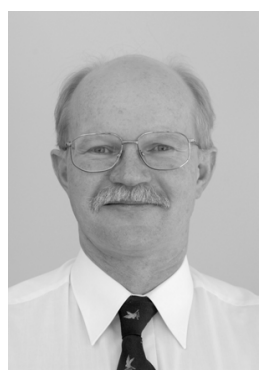

Peter Wolfs (M'80, SM'99) was born in Rockhampton Australia in 1959. He graduated from the Capricornia Institute of Advanced Education in 1980 with a Bachelor of Engineering Degree. He subsequently secured a Master of Engineering degree with the Philips International Institute in the Netherlands in 1981 and a $\mathrm{PhD}$ degree at the University of Queensland in 1992.

His is the Associate Dean (Research) at the Faculty of Engineering and Physical Systems at Central Queensland University. His special fields of interest include rural and renewable energy supply, electric, solar and hybrid electric vehicles and intelligent systems applications in railways. Professor Wolfs is Senior Member of IEEE, a Fellow of Engineers Australia, a Registered Professional Engineer in the State of Queensland and a member of the Railway Technical Society of Australia. 